\title{
ANÁLISE DAS MATRIZES SOBRE ASSOCIATIVISMO CIVIL NORTEADORAS DA FORMAÇÃO DE TRABALHADORES PARA ONGS
}

\author{
ANALYSIS OF THE GUIDELINES ABOUT CIVIL ASSOCIATIONS \\ FOR THE TRAINING OF NGOS WORKERS
}

\author{
Deivis Perez ${ }^{1}$
}

\begin{abstract}
RESUMO
Este artigo apresenta uma pesquisa que teve como objetivo discutir as matrizes teóricas sobre associativismo civil prescritas pelos formadores de um curso de capacitação de trabalhadores para a atuação em organizações não governamentais (ONGs). As indicações sobre associativismo civil realizadas pelos formadores foram analisadas por meio da circunscrição de duas categorias de referências e dados, nomeadas empíricas e analíticas. As categorias empíricas emergiram dos dados recolhidos em campo, nas entrevistas semidiretivas com os formadores e, também, do exame dos documentos norteadores do curso. As categorias analíticas foram construídas por intermédio da revisão da literatura sobre as abordagens de associativismo civil, que são: abordagem norte-americana de Terceiro Setor; abordagem crítica ao Terceiro Setor e desenvolvimento social local (DSL). Ao final do artigo há indicações que poderão apoiar o desenvolvimento de outras pesquisas sobre o tema e, principalmente, saberes acadêmicos que poderão auxiliar o desenvolvimento ulterior de processos formativos de trabalhadores para ONGs.

Palavras-chave: Formação de trabalhadores. Associativismo civil. Organizações não governamentais.
\end{abstract}

\begin{abstract}
This article presents research that aimed to discuss the theoretical frameworks about civil associativism prescribed by the trainers of non-governmental organizations (NGOs) workers. The requirements for civil associations made by trainers were analyzed based on two data and reference categories, named empirical and analytical. The empirical categories emerged from the data collected by means of interviews with trainers and also examining the documents that guided the course. The analytical categories were constructed from the literature review on the approaches of civil associations, which are: North American Third Sector Approach; Critical Approach to the Third Sector and Social Local Development (DSL in the Portuguese acronym). The study presents indications that could support the development of other research on the topic and, mainly academic knowledge for further development of new training processes for NGO workers.
\end{abstract}

Keywords: Worker training. Civil associations. Non-governmental organizations.

${ }^{1}$ Doutor em Educação pela Pontifícia Universidade Católica de São Paulo. Docente do Departamento de Psicologia Evolutiva, Social e Escolar da Universidade Estadual Paulista Julio de Mesquita Filho. E-mail: prof.deivisperez@hotmail.com 


\section{Introdução}

Este artigo tem como objetivo apresentar uma pesquisa acadêmico-científica que foi dedicada à análise e compreensão das matrizes ou abordagens teóricas sobre associativismo civil, prescritas no processo de formação de trabalhadores para a atuação em organizações não governamentais (ONGs). O exame do tema foi feito por meio de recolha, sistematização e estudo de dados sobre as prescrições dos formadores (docentes), acerca das teorias sobre associativismo civil, realizadas em um curso de capacitação de trabalhadores que já atuavam ou pretendiam atuar em ONGs. Esse curso, denominado Formação de Trabalhadores para $O N G s$, foi organizado e realizado por uma ONG sediada na cidade de São Paulo, e teve como foco a capacitação de pessoas para sua gestão e/ ou coordenação de projetos sociais realizados no âmbito dessas instituições e demais organizações da sociedade civil, tais como: organizações de interesse público, organizações sociais, fundações e áreas de responsabilidade social de empresas, organizações sem fins lucrativos, entre outras. Vale mencionar que o curso contava com a presença de profissionais, voluntários e ativistas vinculados ou interessados em trabalhar em ONGs. Neste estudo, não se fez distinção na nomenclatura utilizada para referência aos participantes do curso, isto é, foram chamados de "trabalhadores" todos aqueles que estavam inseridos no processo formativo, considerando que se compreende por trabalho a ação produtiva realizada no mundo com vistas ao alcance de um determinado fim e por trabalhador o sujeito que empreende a ação laboral produtiva, independentemente da relação formal estabelecida entre o trabalhador e a organização na qual realiza a sua atividade.

Antes do relato da pesquisa, é preciso informar que, por solicitação dos participantes, o nome da ONG foi alterado, sendo aqui denominada "ONG Formadora", e também as informações que pudessem identificar os formadores participantes voluntariamente do estudo, sem qualquer prejuízo para o entendimento do conjunto de dados e reflexões que emergiram nesta investigação.

Cumpre destacar que esta pesquisa se insere no contexto mais amplo de um projeto de estudos que tem como objetivo compreender os processos formativos e a própria atividade laboral daqueles que trabalham em ONGs. Existem estudos desenvolvidos sobre a formação de um grupo específico de trabalhadores inseridos em ONGs (PEREZ, 2004; 2009; 2013), entretanto, percebemos que era necessário conhecer o modo como os demais trabalhadores dessas organizações, em particular aqueles que assumem funções de liderança e comando (gestores e coordenadores), são formados e com base em quais perspectivas teórico-práticas de associativismo civil orientam e realizam o seu trabalho. Essa percepção conduziu à elaboração e realização da pesquisa que agora é apresentada.

$\mathrm{O}$ interesse pelo processo formativo e pelas matrizes de associativismo civil, orientadoras da atividade laboral de trabalhadores das ONGs, justifica-se pela ampliação da relevância e presença no Brasil destas organizações. De acordo com pesquisa divulgada no final de 2012 pelo Instituto Brasileiro de Geografia e Estatística (IBGE), havia no país, em 2010, mais de duzentas e noventa mil ONGs que empregavam mais de dois milhões e cem mil trabalhadores. Além das pessoas que possuem vinculo empregatício formal com ONGs, estima-se que $16 \%$ da população economicamente ativa do Brasil realiza atividades voluntariamente, todos os anos, nessas organizações. Ainda, é preciso notar que a atuação das ONGs e dos seus trabalhadores estão relacionadas a campos tão distintos e estratégicos quanto à educação, cultura, saúde, assistência social, ao esporte, à comunicação, pesquisa, ao lazer, à religião, entre outros. Parece evidente, portanto, que se não houver um adequado conhecimento a respeito dos referenciais teóricos e práticos adotados por essas organizações e seus trabalhadores acerca de como a sociedade civil se organiza e de que forma analisam a associação dos cidadãos, estarão ausentes as condições básicas para uma análise profunda, crítica e abrangente sobre o alcance, qualidade, relevância e limitações do trabalho desenvolvido, no sentido da construção de uma sociedade democrática.

A escolha do curso Formação de Trabalhadores para ONGs, como espaço para a recolha dos dados desta pesquisa, justifica-se por ser o único oferecido na cidade de São Paulo nos últimos dois anos (2011-2012). Este curso formou três turmas de coordenadores e gestores para ONGs, sendo a primeira 
em 2011 e a última no segundo semestre de 2012. O curso foi escolhido também por ter sido elaborado e realizado por uma ONG que, hipoteticamente, tem interesse e potencial para favorecer um processo formativo de gestores e coordenadores, sintonizado com as principais práticas e teorias que circulam contemporaneamente sobre associativismo civil.

Este artigo está organizado em quatro subseções, além desta introdução e das considerações finais, em que abordamos, sucessivamente: a) a perspectiva metodológica e o contexto de recolha dos dados; b) a definição de organizações não governamentais (ONGs); c) apresentação das categorias analíticas, previamente delimitadas, d) a análise e discussão dos dados recolhidos acerca das prescrições e indicações apresentadas pelos formadores de trabalhadores para ONGs sobre associativismo civil.

\section{Perspectiva metodológica da pesquisa e contexto de recolha dos dados}

No tocante à metodologia, optamos por uma pesquisa qualitativa, em que os dados coletados são mais descritivos e procuram captar o discurso e a percepção das pessoas sobre um problema ou situação. Corroborou a indicação de Antonio Chizzotti, para quem a adoção da abordagem qualitativa de pesquisa deve ocorrer nos casos em que o pesquisador considerar que "o mundo deriva da compreensão que as pessoas constroem no contato com a realidade nas diferentes interações humanas e sociais" (CHIZZOTTI, 2010, p. 69). Portanto, nesta abordagem de pesquisa, a ênfase das interpretações e análises do pesquisador se dá no sentido que os seres humanos conferem a um determinado fenômeno do qual partilham.

Com base nos aspectos acima mencionados e no estudo dos diferentes tipos de pesquisa qualitativa, decidimos pela realização de um estudo de caso, que é um tipo de pesquisa utilizado frequentemente nas Ciências Sociais. A pesquisadora Marli André sinaliza que o estudo de caso caracteriza-se por ser um "[...] estudo em profundidade de um fenômeno, com ênfase na sua singularidade [...]" (ANDRÉ, 2005, p. 19). Nesta pesquisa, realizou-se o que Stake (1995 apud ANDRÉ, 2005) denominou "estudo de caso instrumental", em que o interesse do pesquisador é o exame de um tema amplo que a análise de um caso particular ajudará a elucidar. O que se pretendia com a pesquisa, era, exatamente, conhecer o modo como um grupo de formadores de trabalhadores para ONGs aborda as teorias sobre associativismo civil em um processo formativo específico.

Em seguida, foram selecionados os instrumentos, ou procedimentos de coleta de dados, da pesquisa, a saber: revisão crítica da literatura pertinente ao tema; entrevistas individuais e coletivas de tipo semidiretivas; e análise de documentos orientadores do trabalho dos formadores de trabalhadores para ONGs. A entrevista foi adotada porque representa, de acordo com Marli André (1986), um instrumento básico da pesquisa qualitativa que permite ao entrevistado discorrer sobre o tema sugerido, por meio de suas vivências e percepções. Foi utilizada a entrevista de tipo semidiretiva, porque se buscou garantir a identificação da percepção dos entrevistados sobre alguns aspectos, considerados centrais, do tema estudado. A entrevista semidiretiva "é aquela que parte de certos questionamentos básicos, apoiados em teorias e hipóteses que interessam à pesquisa, e que, em seguida, oferecem amplo campo de interrogativas [...]" (TRIVIÑOS, 1995, p. 146).

Participaram desta pesquisa, por meio das entrevistas semidiretivas, três sujeitos que contribuíram voluntariamente. Foram realizadas entrevistas individuais e coletivas com dois formadores do curso e com o profissional responsável pela sua coordenação, que também é o principal gestor da ONG Formadora. Analisou-se o Plano Pedagógico e as ementas dos diferentes módulos do curso; os manuais ou apostilas do formador, com a descrição das atividades que deveriam ser realizadas nas aulas; as ementas das disciplinas do curso e a proposta estratégica da ONG que o organiza e realiza.

É necessário apontar que a carga horária total das aulas teóricas do curso era de 128 horas, realizadas aos sábados, em período integral, distribuídas em três módulos de aproximadamente 46 horas cada. À carga horária das aulas teóricas eram acrescidas 64 horas para a elaboração, pelos participantes, de um projeto de gestão, que deveria ser implementado em uma ONG. Tal projeto foi construído e desenvolvido em grupos de alunos, sob orientação de um formador do curso. A duração das atividades formativas era de 
aproximadamente quatro meses. Portanto, o trabalhador em formação que concluiu o curso recebeu um certificado em que foram registradas 192 horas. Os três módulos de aulas teóricas do curso eram, nomeadamente: a) Módulo 1 - Apresentação e proposta de debates em torno do tema contexto social, político e econômico, com 52 horas de duração; b) Módulo 2 - Elaboração de Projetos Práticos de Educação, com 40 horas de duração. $\mathrm{O}$ foco do segundo módulo era instrumentalizar o participante para a elaboração de um projeto socioeducacional a ser desenvolvido concretamente em uma ONG; c) Módulo 3 - Desenvolvimento do Projeto Prático de Educação em ONG, com 36 horas de duração. É o momento do curso em que o aluno inicia a implantação do projeto criado no módulo anterior.

A análise das prescrições dos formadores aos participantes do curso Formação de Trabalhadores para ONGs foi realizada a partir da circunscrição de duas categorias de referências e dados, denominadas empíricas e analíticas ou teóricas. As categorias analíticas foram estabelecidas previamente, antes mesmo da coleta de dados em campo. A delimitação prévia de categorias analíticas ocorreu porque há ampla literatura acadêmica disponível sobre associativismo civil, que deve ser analisada e discutida em quaisquer processos formativos de trabalhadores para ONGs, ao nosso ver. Estas categorias são: Desenvolvimento Social Local (DSL) e Terceiro Setor, que inclui a Abordagem Norte-Americana de Terceiro Setor e a Abordagem Crítica ao Terceiro Setor. O DSL não é exatamente uma perspectiva de associativismo civil, trata-se de abordagem teórica que tem sido incorporada por trabalhadores de ONGs na realização de suas ações.

Com base nas reflexões teóricas, favorecidas pelo exercício de delimitação das categorias analíticas, pudemos verificar as abordagens de associativismo civil que estavam presentes no curso estudado e de que forma eram trabalhadas pelos seus formadores. As análises não ficaram restritas ao que foi previamente encontrado na literatura. Buscamos realizar a identificação das denominadas categorias empíricas, considerando as informações que emergiram do processo de recolha de dados. Isso porque, de acordo com Franco (2008), são exatamente dos dados de campo que se originam os elementos empíricos de análise.
Na seção que segue são apresentadas as diferentes formas de compreender o que são as ONGs e a definição adotada nesta pesquisa.

\section{O que são as Organizações Não Governamentais / ONGs}

O conceito de $\mathrm{ONG}$, bem como as matrizes teóricas e práticas sobre associativismo civil que orientam o trabalho destas organizações, têm sido alvo de grande controvérsia entre os ativistas e autores que discutem o tema. Em todo o mundo, analisar e debater questões sobre o papel e a atuação das ONGs é assunto complexo. A despeito disso, pode-se considerar que a denominação "Organização Não Governamental” (ONG) parece ter sido criada pela Organização das Nações Unidas (ONU) após a Segunda Grande Guerra, para nomear e definir o papel de organismos que representavam setores da sociedade não vinculados aos governos e às empresas privadas. As organizações daquele período histórico, que a ONU passou a denominar ONGs, atuavam essencialmente na área da saúde, em lutas pela democracia e pela garantia dos direitos políticos, sociais e econômicos e no apoio a reivindicações de paz ou campanhas contra guerras que países centrais do capitalismo declaravam contra os países percebidos como periféricos.

É importante mencionar que há, hoje, um conjunto de termos e siglas utilizadas no Brasil que se referem às organizações criadas e mantidas por iniciativa da sociedade civil. As principais terminologias usadas são: Organizações ou entidades sociais (OS); organizações da sociedade civil (OSC); organizações sem fins lucrativos (OSFL); organizações ou entidades filantrópicas (OF); organizações da sociedade civil de interesse público (OSCIP); entidades assistenciais (EA); entidades beneficentes de assistência social (EBAS); entidades de utilidade pública; além de organizações não governamentais (ONGs), e tantas outras menos correntes. Sabemos que muitas dessas definições continuam sendo utilizadas ou porque foram consagradas na literatura especializada ou em função de seu uso sistemático na mídia. Outras definições dizem respeito a títulos que são regulados e conferidos, com base em decretos e leis específicas, pelo poder público, como é o caso das entidades filantrópicas, OSCIPs e OS. 
Neste trabalho adotamos a sigla ONG, porque ela parece representar tanto no imaginário popular quanto na literatura especializada o que se compreende por organizações da sociedade civil voltadas para o trabalho social em suas diferentes expressões e áreas (meio ambiente, educação, saúde, defesa de direitos, etc.). Poderíamos utilizar a denominação "organização da sociedade civil", mas ela costuma incluir em seu bojo os sindicatos de trabalhadores, as fundações empresariais, as escolas e universidades comunitárias. Preferimos adotar ONG como a sigla ou a expressão que mais diretamente nos remete às organizações estruturadas por meio do esforço e do interesse dos cidadãos, que se voltam para atuar em áreas do campo social consideradas significativas pelos grupos que as criaram e mantêm.

No Brasil, as primeiras ONGs concebidas como instituições de associação de cidadãos e de expressão da organização da sociedade civil, se comparadas ao que se conhece hoje, teriam surgido para apoiar o necessário combate à ditadura civil-militar, próximas dos movimentos sociais tradicionais dos anos 1960 e 1970 (GOHN, 2001). A partir de meados da década de 1980, com maior ênfase nos anos 1990, as ONGs ganharam força e passaram a configurar de forma mais sistematizada seu campo de atuação. Seu papel e sua identidade atuais foram fortemente influenciados pelas alterações políticas e econômicas observadas em fins do século XX. Entre as transformações que contribuíram para o atual perfil das ONGs brasileiras, está o fenômeno que ficou conhecido como globalização.

O termo globalização, visto como conceito utilizado para explicar parte da realidade social, tem sido empregado com abrangência crescente por organismos internacionais, teóricos, políticos e pela mídia, de modo geral. A despeito desse uso corrente do termo, nota-se que não há consenso acerca do seu exato significado e sentido. Analogamente à Marina Graziela Feldmann (2003, p. 09), consideramos que se trata de um conceito polissêmico, que "[...] abrange vários sentidos e interpretações. É acompanhado pela dimensão da complexidade e da ambivalência".

Corroboram essa percepção sobre a polissemia em torno da palavra e da noção de globalização as indicações de Nicholas Burbules e Carlos Alberto Torres (2004), que consideram a existência de abordagens e formas de compreensão extremamente dife- rentes do termo em questão. Os autores apontam que há pensadores que consideram que a globalização diz respeito exclusivamente ao surgimento de instituições supranacionais. Para outros, ainda segundo Burbules e Torres, a globalização estaria relacionada aos processos econômicos globais e seus impactos nos processos mundiais de produção, comércio, fluxo de capitais, entre outros.

Apesar de não existir consenso sobre o termo, é possível observar, na literatura especializada, a existência de algumas abordagens dominantes. Aparentemente, a visão de Ladislau Dowbor (2001a) sintetiza as diferentes perspectivas e concepções existentes. Para o autor, a noção geral de globalização se desdobraria em: a) globalização de produtos - produção, compra e venda de produtos em âmbito global; b) globalização da comunicação - desenvolvimento de tecnologias que permitiram alterar significativamente as formas de organização, acesso e transmissão de conhecimentos, além da ampliação espantosa de possibilidades de conexão entre pessoas; c) globalização financeira - possibilidade de transferência rápida de grandes quantidades de dinheiro entre diversos países, realizadas por grupos empresariais transnacionais, que desequilibram as economias locais e cujas principais vítimas são os estados nacionais e suas populações, em particular, as parcelas mais empobrecidas; d) globalização cultural - representada pelo intercâmbio, pelas trocas e pelo contato entre diferentes culturas.

A radicalização e ampliação do processo de globalização teria feito emergir novas áreas, antes inexistentes ou pouco significativas, para a atuação das ONGs, como a luta pela democratização do acesso às tecnologias da informação e comunicação e contra a exclusão digital; a fiscalização e acompanhamento da atuação de empresas globais, em especial no tocante aos direitos das populações locais; a educação de parcelas empobrecidas da população, bem como ações relacionadas à assistência social e realização de ações dedicadas, principalmente, à promoção e prevenção da saúde dos grupos pauperizados. Em certo sentido, a globalização abriu campos de ação para as ONGs brasileiras que não existiam até o final do regime ditatorial civil-militar e favoreceu o surgimento do fenômeno que ficou conhecido como o fim das ideologias (esquerda versus direita; capitalistas versus socialistas), que permitiu 
às ONGs um reposicionamento no cenário político e social do país, deixando o caráter contestador, observado entre os anos 1960 e 1970, assumindo uma postura menos crítica aos governos (federal, estadual e municipal) e mais sintonizada com as práticas e pensamento do mundo corporativo.

Foi por meio do fortalecimento do processo de globalização e do movimento neoliberal pela minimização do Estado, em fins dos anos 1990 no Brasil, articulado à redução de oportunidades de acesso da população aos serviços relacionados às áreas do chamado Estado do Bem-Estar Social (educação, saúde e assistência social), que as ONGs passaram a trabalhar, com grande ênfase, na criação e oferta de serviços. As políticas públicas de caráter neoliberal, especialmente aquelas efetivadas no período do governo do ex-presidente Fernando Henrique Cardoso (FHC), e o processo de globalização levaram o país a uma gradual privatização de diversos setores, antes sob controle estatal, tais como: o ensino superior, parte da educação infantil, a telefonia fixa e móvel e as telecomunicações, o transporte público de massa sobre trilhos e a saúde reparativa, entre diversos outros. As áreas voltadas para as parcelas da população que possuíam recursos para custear os serviços desejados (telefonia, telecomunicações, ensino superior e parte dos serviços dedicados à reparação da saúde) acabaram sendo absorvidas pela iniciativa privada.

Os setores que não apresentavam perspectiva de retorno financeiro significativo para as empresas privadas, como a alfabetização de adultos, a educação infantil, a prevenção, promoção e reparação de saúde das camadas empobrecidas da população continuaram sob a responsabilidade do Estado, que identificou nas ONGs as parceiras adequadas para transferir recursos e assumir a prestação de serviços ou substituir atividades próprias do Estado. Tratou-se de um período de fortalecimento das ONGs, sustentado pela necessidade de atendimento aos grupos empobrecidos da população e, principalmente, fundado na crescente desresponsabilização estatal em relação à garantia de direitos e oferta de serviços básicos à população observados até o final da chamada era FHC.

Além dos aspectos acima, o perfil das ONGs brasileiras é marcado, em grande parte, pelas origens de cada organização ou de grupos delas. No Brasil, há as que surgiram por meio da síntese de movimentos ligados à direita conservadora; outras nasceram de movimentos sociais críticos e combativos ao Estado, em especial no período da ditadura; ainda, de igrejas e grupos religiosos - protestantes, católicos, espíritas etc.; e, recentemente, do movimento denominado responsabilidade social, que levou a iniciativa privada a apoiar financeiramente e logisticamente ONGs e criar Institutos, Fundações e assemelhados, ligados ao que se denomina Terceiro Setor.

Há estudiosos que ponderam que as ONGs seriam a expressão da busca empreendida pela sociedade civil, no sentido de "assumir diretamente a solução de alguns dos seus problemas, sem esperar que o faça o Estado, ou a mão invisível do setor empresarial" (DOWBOR, 2001b, p. 63). Entretanto, é preciso reconhecer, em sintonia com Maria da Glória Gohn (2005), que as ONGs atuais têm um perfil pouco politizado, de baixa combatividade ao modelo capitalista de organização da sociedade. O grande interesse dessas organizações parece ser o estabelecimento de parcerias com o Estado e com a iniciativa privada. Em parte, devido à ausência de politização e do interesse em prestar serviços financiados pela iniciativa privada e governos, as ONGs tendem a realizar projetos com foco em valores amplos como a solidariedade, democracia, igualdade e defesa da cidadania.

Não se nega a existência de ONGs que se afastam e se opõem ao perfil descrito, como aquelas que combatem e criticam o projeto societal capitalista, ou as vinculadas aos movimentos sociais e comunidades de base, que procuram apoiar e canalizar as reivindicações populares e contrapor os interesses públicos às ações inadequadas e arbitrárias de órgãos e agentes governamentais e das empresas privadas.

É forçoso reconhecer que a complexidade e a diversidade de origens, características, áreas de atuação e posicionamento político das ONGs se apresentam como elementos complicadores para o estudo, compreensão e delimitação dessas organizações. Mas não se pode perder de vista que há, por meio da realização de pesquisa e da produção de saberes acadêmico-científicos, uma oportunidade de apoiá-las na definição de um campo de atuação e posicionamento político-ideológico menos difuso e mais crítico em relação ao Estado e ao mercado, e contribuir, dessa forma, com a visão de que o papel das ONGs deve estar ligado à associação, organização, mobilização e educação de sujeitos e grupos para: 
a) A participação democrática ativa, e não apenas representativa, na gestão dos recursos comunitários sob gestão dos órgãos e representantes dos governos.

b) A demanda, o questionamento e a avaliação da gestão dos recursos sociais e dos serviços oferecidos à população pelos governos e seus agentes.

c) O questionamento do modelo capitalista de organização social.

d) A geração de renda, de forma solidária, pela população empobrecida, bem como a oposição ao modelo de organização do trabalho focado nos interesses do capital e na desarticulação e despolitização dos trabalhadores.

Em hipótese alguma as ações de ONGs devem substituir, temporariamente ou em definitivo, as atividades próprias do Estado, nos campos da educação, saúde e assistência social (Estado do Bem-Estar Social). As ONGs podem realizar ações exemplares nestes setores e tornar disponíveis tecnologias sociais inovadoras para organismos governamentais, mas jamais ocupar o espaço de garantia de direitos e serviços à população, que é próprio da dimensão estatal. Sabemos que há teóricos e trabalhadores dessas organizações que defendem o processo denominado publicização, ou seja, o incentivo à substituição de órgãos e serviços estatais por ações empreendidas por ONGs na prestação de serviços em áreas fundamentais, em uma tentativa de diminuir o Estado do Bem-Estar Social.

A definição e, principalmente, o papel das ONGs descrito neste texto diverge da visão dos gestores e teóricos orgânicos da abordagem de associativismo civil denominada Terceiro Setor, entre os quais estão Léster Salamon (2005; 2012), Rubem César Fernandes (2005), Andres Falconer (1999; 2001) e Eduardo Szazi (2006). A perspectiva destes e de outros autores de mesma visão será abordada adiante, no tópico que trata das categorias de associativismo civil.

\section{Categorias Analíticas: As abordagens de associativismo civil}

Neste momento, vale relembrar que a temática geral da pesquisa refere-se à identificação das principais matrizes teóricas sobre associativismo civil que são prescritas por formadores de trabalhadores para
ONGs, em particular, para a gestão dessas organizações e dos seus projetos.

As principais abordagens e categorias analíticas identificadas na literatura acadêmica pertinentes ao tema e adotadas para nortear a análise teórica do objeto desta pesquisa foram: a) Terceiro Setor, que se desdobra em duas perspectivas - abordagem norte-americana e abordagem crítica ao Terceiro Setor; desenvolvimento social local (doravante DSL). É preciso lembrar que essas abordagens estão relacionadas ao modo com os cidadãos se associam, ao trabalho das ONGs e ao debate que as envolve, mas que não necessariamente se constituem em perspectivas teóricas unicamente estruturadas a partir dessas organizações.

\section{O Terceiro Setor}

\section{Abordagem Norte-Americana de Terceiro Setor}

O conceito de Terceiro Setor tem sido utilizado com ênfase e abrangência crescentes nos últimos trinta e cinco anos por organismos internacionais, como a ONU, por teóricos (SALAMON, 2005; LANDIM, 1993; HENDERSON, 1996; DOWBOR, 2001) e pelos meios de comunicação, de modo geral. O termo é usado para referir o conjunto de organizações nascidas por meio da iniciativa da sociedade civil, que são nomeadas das mais distintas formas no Brasil e exterior. Nesta pesquisa, conforme citado anteriormente, optou-se pelo termo ONG como referência a todas as organizações da sociedade civil.

A abordagem norte-americana do Terceiro Setor (PEREZ, 2004; 2009) foi assim nomeada em função de seus principais pensadores serem oriundos dos Estados Unidos ou defenderem o modelo e a tradição teórica e prática de associativismo civil norte-americano. Como fundamento teórico da abordagem, apresentam-se as ideias originais de Alexis de Tocqueville (1835/1998) revisitadas, ao longo do século XX, por Putnan (1993), Fukuyama (1992) e Salamon (2005).

Tocqueville viajou, na primeira metade do século XIX, pelos Estados Unidos observando e elaborando análises acerca da democracia daquele país. Para ele, a liberdade que possuíam os cidadãos norte-americanos para a formação de associações 
seria sinônimo de liberdade política e atuava como base para a construção daquilo que se denominou como democracia ideal. Esse ideário associativista tocquevilliano é que estaria na origem do que chamamos Terceiro Setor.

O centro do pensamento de Tocqueville, de orientação conservadora da ordem política, econômica e social capitalista, aponta que uma democracia sólida somente poderia ser construída por meio de Estados, entendidos aqui como Governos, com menor poder tirânico (termos do próprio autor); livre iniciativa de mercado com defesa da propriedade privada e concentração de riquezas por parcela minoritária da população (proprietários dos meios de produção) e, por fim, ênfase absoluta na importância de os indivíduos se associarem livremente para defender seus interesses.

O direito de livre associação é que garantiria o fortalecimento e manutenção das democracias, pois, para Tocqueville, a pressão exercida pelas associações civis em relação ao Estado garantiria que este não se constituísse de forma autoritária e despótica. No que diz respeito à economia, o autor mostrou-se contra uma sociedade em que a igualdade econômica e a justiça social fossem reinantes. Para ele, sociedades economicamente igualitárias poderiam ameaçar a democracia, dado o risco iminente de surgimento de uma tirania da maioria, composta pelos trabalhadores.

O pensador francês afirmava que a manutenção da ordem social estaria garantida se as organizações de livre associação dos cidadãos defendessem interesses e direitos particulares de pequenos grupos. A organização e articulação de grandes grupos de cidadãos eram vistas de forma negativa, dada a necessidade de evitar o surgimento de insurreições da maioria da população ou o desenvolvimento de um Estado despótico. É relevante citar que, para o autor, Estado despótico era sinônimo de Estado Socialista.

Tocqueville opunha-se radicalmente a quaisquer formas socialistas de organização das massas, isto é, opunha-se à auto-organização ampla dos trabalhadores (maioria) para reivindicar justiça social e igualdade de distribuição das riquezas junto às elites dominantes (minoria).

Durante o século XX, teóricos como Robert Putnam (1993) e Fukuyama (1992) retomaram as proposições de Tocqueville para tentar justificar a percepção de que a sociedade, em seu conjunto, e as organizações nascidas em seu interior não somente se aproximariam, como também se constituiriam em um todo único e indissociável. Nessa perspectiva, teríamos os cidadãos organizados, Estado e empresas privadas, em busca de objetivos comuns. De fato, mesmo nos Estados Unidos, é somente a partir de meados da década de 1970 que a noção de Terceiro Setor passa a ser mais amplamente utilizada para designar o conjunto de organizações da sociedade civil, as ONGs.

Segundo Carlos Montaño (2007), Terceiro Setor seria um termo cunhado por autores com visão liberal ligados aos Estados Unidos, maior país capitalista do mundo, para designar o conjunto de organizações de cidadãos associados livremente de acordo com seus interesses particulares. Montaño, em seu estudo crítico acerca do Setor, chega a indicar a autoria do termo, que teria sido "[...] cunhado nos EUA, em 1978, por John Rockfeller II, capitalista norte-americano". (MONTAÑO, 2007: p. 83).

Os principais representantes dessa perspectiva estão ligados ao Johns Hopkins Institute for Policy Studies, entre os quais Léster Salamon é o pesquisador de maior destaque. Contemporaneamente, a abordagem norte-americana de Terceiro Setor e seus autores não buscam ou estimulam a transformação social e não questionam o modelo capitalista de sociedade. O objetivo principal das organizações do Terceiro Setor, em particular as ONGs, seria apenas aperfeiçoar as formas de ordenamento da sociedade civil, pois, no dizer de Salamon $(2005$, p. 101) “[...] um dos grandes desafios do Terceiro Setor não é criar estruturas sociais inteiramente novas, mas aplicar novas formas de associação às estruturas tradicionais da vida comunitária".

Salamon afirma que aquilo que define o Terceiro Setor, determina e confere unidade ao conjunto das suas organizações, é a incorporação de uma gama de valores difusos, como "altruísmo, compaixão, sensibilidade para com os necessitados e compromisso com o direito de livre expressão" (SALAMON, 2005, p. 92). No entanto, acima dos valores que incorpora, o Terceiro Setor tem como fundamentos:

A iniciativa individual, em particular a iniciativa individual em prol do bem público, a ideia de que os seres humanos têm a capacidade e a obrigação 
de agir por autoridade própria a fim de melhorar suas vidas e as dos outros, assumindo as rédeas para fomentar o bem-estar geral. (SALAMON, 2005, p. 92).

A visão de Salamon parte de uma perspectiva individualista e personalista de associativismo, pressupondo que, por meio de cada indivíduo e de seus interesses particulares, é que deveria se organizar o processo de articulação e associação dos cidadãos. $\mathrm{O}$ autor, ainda, considera que todas as pessoas e todos os setores econômicos e produtivos da sociedade estariam em busca de um objetivo comum, considerado bom por todos os segmentos. O pensamento de Salamon sinaliza para uma suposta unidade de interesses dos múltiplos setores sociais, em uma simplificação e negação da complexidade de interesses e conflitos existentes em quaisquer coletivos humanos, em particular nas sociedades capitalistas, que, historicamente, têm oposto os grupos enriquecidos aos enormes contingentes de trabalhadores e grupos empobrecidos da população. O teórico, portanto, sugere que os interesses articulados de grandes setores da sociedade sejam colocados de lado, em favor da organização de pequenos grupos em defesa de interesses específicos. O autor norte-americano compreende, ainda, que a boa qualidade de vida e o bem comum sejam os interesses principais de todos, e que isso somente pode se constituir por meio dos esforços colaborativos dos mais diferentes segmentos sociais, como o Estado, o setor empresarial e o Terceiro Setor, composto pelas ONGs.

É importante ressaltar que Salamon rejeita quaisquer perspectivas por ele denominadas de "ideológicas" que sejam críticas às suas concepções de associativismo, de sociedade e ao próprio Terceiro Setor, isto é, outros autores que visualizam no Setor algo além da busca do bem comum, estariam, portanto, analisando e compreendendo incorretamente a realidade das ONGs. Vincular o Terceiro Setor ao projeto capitalista de sociedade, como costumam apontar os críticos é, então, uma inadequada ideologização do debate por Salamon.

As ONGs, nessa abordagem, devem evitar o confronto e o questionamento aos organismos governamentais e às ações das empresas privadas. A proposta é a busca incessante de parcerias para a realização de projetos sociais pontuais, de curta e média duração. Em síntese, para Salamon e outros autores do Terceiro Setor, nós já vivemos em uma organização social perfeita que, eventualmente, necessita de pequenos ajustes e correções, que podem e devem ser conduzidas pelas ONGs e demais organizações deste Setor.

A sintonia e funcionalidade da abordagem norte-americana de Terceiro Setor ao projeto capitalista de sociedade ficam explicitas, por exemplo, nos escritos de Andrés Falconer $(1999 ; 2001)$, autor e pretenso ideólogo brasileiro do Setor, segundo o qual a saída para o fortalecimento das ONGs e do Terceiro Setor brasileiro seria a adoção de medidas que se aproximam das propostas de Salamon, a saber: a) postura, por parte das ONGs, análoga à das empresas na competição por recursos públicos e privados; b) percepção do público atendido pelas ONGs como clientes - e não cidadãos de direito; c) associação das organizações em redes de mútua ajuda, objetivando a defesa de interesses de grupos particulares. Nesse aspecto, tanto a visão de Falconer como a de Salamon têm recebido críticas, à medida que sugerem não a defesa dos direitos de toda a coletividade de indivíduos, mas de grupos particulares.

Entre os autores ou atores sociais nacionais que abordam o Terceiro Setor, também destaca-se Rubem César Fernandes. Bastante influenciado por Salamon, costuma apontar as ONGs como espaço legítimo para o exercício da cidadania. Durante a década de 1990 e início dos anos 2000, Fernandes questionava firmemente a ação de organizações críticas ao governo FHC e ao modelo neoliberal de estruturação societal, preferindo reforçar o papel supostamente integrador das ONGs e do Terceiro Setor como espaço de práticas solidárias e caritativas. Fernandes sustentou com grande ênfase a necessidade de colaboração entre as organizações do Terceiro Setor, empresas e governo.

Considerando o que foi exposto, podemos afirmar que a visão norte-americana de Terceiro Setor se constitui como instrumento de negação da possibilidade de disputas políticas e econômicas entre grupos e classes sociais e, mais especificamente, entre grupos enriquecidos e as classes subalternas e pauperizadas. Essa negação é mais um instrumento de manutenção da ordem social, regida por interesses do capital, visto que "em uma sociedade tão marcantemente desigual, se o conflito não é 
parte constitutiva da política, as classes subalternas jamais terão a oportunidade de alterar as diferentes assimetrias existentes" (NAVARRO, 2002, p. 197).

Dada a centralidade dessa perspectiva de associativismo civil nos debates que envolvem as ONGs, é fundamental que os trabalhadores, participantes de um processo formativo para atuação em ONGs, como este que estamos analisando, conheçam, em profundidade, seus pressupostos e questionem a perspectiva socioeconômica e política que se encontra subjacente aos escritos de seus autores.

\section{Abordagem Crítica ao Terceiro Setor}

A abordagem crítica ao Terceiro Setor (PEREZ, 2004; 2009) refere-se aos escritos de autores que se opõem à própria noção de Terceiro Setor ou questionam, firmemente, as atuais formas de expressão de solidariedade que as organizações e ações do Terceiro Setor representam. O teórico norte-americano James Petras (1999), no plano internacional, é o principal pensador da abordagem crítica.

Petras costuma apontar que a atuação das organizações do Terceiro Setor teriam como resultado um efeito favorável aos regimes capitalistas atuais. A preocupação exacerbada das ONGs com a resolução de problemas localizados é percebida por Petras como elemento que afasta os cidadãos do debate sobre as grandes questões da sociedade. $\mathrm{O}$ autor acredita que o fato de ONGs inseridas "na luta contra o imperialismo, contra o capital, não receberem financiamento do Estado ou de instituições financeiras" (Petras, 2000, p. 88) se constitui em forte indicativo do engajamento do Terceiro Setor ao projeto capitalista de sociedade.

$\mathrm{O}$ afastamento gradual de grande parte das ONGs em relação aos movimentos sociais é outro aspecto questionado pelo autor. Segundo ele, essas organizações optaram pela aproximação de mecanismos e órgãos internacionais de financiamento ligados ao capital em detrimento da relação com movimentos populares de base. Petras, ainda, sinaliza para a possível articulação e estabelecimento de nexos entre o processo de desresponsabilização dos Estados pelos serviços sociais e de bem estar das populações e o crescimento do número de ONGs em diversos países.
No Brasil, Carlos Montaño é o principal representante deste segmento. Sua tese de doutorado, Terceiro Setor e a questão social, é uma longa e vigorosa análise do que chamou de ideário de autores do Terceiro Setor que, segundo ele: a) se mostram incapazes de conferir contornos conceitualmente claros ao Setor; b) costumam ocultar, em seus escritos, a análise histórica dos processos que levaram à construção das organizações da sociedade civil e ONGs hoje existentes.

As percepções de Montaño aproximam-se das ideias de Petras. Suas análises e críticas estão centradas na Abordagem Norte-Americana, apresentada anteriormente. $\mathrm{O}$ autor rejeita a aproximação das noções de movimento social e de ONGs realizada, por exemplo, por Maria da Glória Gohn (2000). Os movimentos sociais estariam, na compreensão de Montaño, identificados com as lutas das comunidades de base e com a transformação social, ao contrário do que ele vê na ação e propostas das ONGs e do Terceiro Setor, de modo global.

Petras e Montaño, em síntese, entendem que o Terceiro Setor centra sua ação e discurso na autoajuda das comunidades pobres, o que as despolitiza e contribui para sua desmobilização. Atua nos sintomas (fome, delinquência, uso de drogas) e nunca no desvelamento e transformação das causas do empobrecimento e enfrentamento dos problemas sociais.

Montaño (2007, p, 262) admite a "necessidade de que, no âmbito da sociedade civil [...] as pessoas, os movimentos comunitários, os grupos de interesse ou categoriais, participem ativamente do processo de lutas sociais". O autor percebe a atividade da sociedade civil como motor da história, de acordo com os pressupostos marxianos que adota. Assim, pensa a sociedade civil organizada como uma "[...] esfera, um espaço da totalidade social, portanto, necessariamente, articulada às outras esferas, particularidades do universal" (MONTAÑO, 2007, p. 09). Sua negação ao Terceiro Setor está basicamente centrada na percepção de totalidade social que, para ele, se opõe frontalmente à noção de setores sociais (primeiro setor $=$ Estado, segundo setor $=$ mercado, terceiro setor = sociedade civil organizada) que, acredita, o Terceiro Setor defende nos dias correntes.

A sociedade civil, portanto, não poderia constituir-se, para o autor em estudo, em um sujeito único que atua em lutas pelo desenvolvimento social. Isso 
porque a própria sociedade é concebida por Montaño como arena de lutas dos diversos atores sociais. Esses embates não aconteceriam entre sociedade civil, Estado e mercado (os três setores), mas por "sujeitos individuais (homens e mulheres) e coletivos (grupos e organizações) em diversos espaços ou esferas da sociedade total, seja na sociedade civil, no Estado, na esfera produtiva, no espaço de consumo, na vida cotidiana" (MONTAÑO, 2007, p. 277).

Outro autor que se aproxima da Abordagem Crítica é o sociólogo Ricardo Antunes, referindo-se, de forma breve, à questão do Terceiro Setor em $O s$ Sentidos do Trabalho. Preocupado com a problemática que envolve o mundo do trabalho, Antunes não se dedica a definir e delimitar o Terceiro Setor. De todo modo, apresenta crítica contundente, merecida de nota, discordando daqueles que conferem relevância ao Terceiro Setor no cenário e na economia global. Ele aproxima as abordagens de Terceiro Setor e Economia Solidária, enfatizando as relações de ambas com o mundo do trabalho. Antunes aponta que tanto o Terceiro Setor quanto as expressões da Economia Solidária seriam funcionais ao capital porque incorporam, ainda que de forma bastante limitada, parcelas de trabalhadores desempregados, em particular, devido ao desemprego estrutural.

O autor não concebe as atividades do Terceiro Setor e da Economia Solidária como alternativas à lógica capitalista; ao contrário, vê proximidade dessas atividades em relação a esse sistema, por considerar que ambas (mais enfaticamente o Terceiro Setor) assumiriam funções do Estado ao atuar de modo a reforçar a falta de interesse do sistema para com a questão social e com os desempregados.

Antunes conclui as suas reflexões sobre o Terceiro Setor e a Economia Solidária afirmando que:

quando concebidas como um momento efetivo de transformação social em profundidade, elas acabam por converter-se em uma nova forma de mistificação que pretende, na hipótese mais generosa, 'substituir' as formas de transformação radical, profunda e totalizantes da lógica societal por mecanismos mais palatáveis e parciais, de algum modo assimiláveis pelo capital. E na sua versão mais branda e adequada à ordem pretendem em realidade evitar as transformações capazes de eliminar o capital. (ANTUNES, 2002, p. 114).
Em síntese, a análise dos críticos ao Terceiro Setor se refere, de forma central, à funcionalidade do Setor aos interesses capitalistas. Consideramos que o Terceiro Setor é uma das formas de analisar o associativismo civil e orientar o trabalho das ONGs, vinculado ao projeto capitalista de sociedade.

Há outras possibilidades de compreender e conduzir o trabalho dessas organizações. Por isso, as críticas à noção de Terceiro Setor não se desdobram neste artigo à negação da relevância das ONGs ou da necessidade de os cidadãos se organizarem para a defesa e luta por seus direitos. É preciso, sim, negar e reagir à visão, que se pretende única, de autores e atores do Terceiro Setor que reservam às ONGs um papel funcional e uma atuação docilizada em relação ao projeto capitalista de sociedade.

\section{Desenvolvimento Social Local - DSL}

A abordagem teórico-prática de associativismo civil, denominada Desenvolvimento Social Local (DSL), possui fortes vinculações com as ONGs, apesar de não ter como foco único aspectos pertinentes a essas organizações. Sua inclusão neste estudo deveu-se ao fato de os seus teóricos terem apresentado contribuições significativas para pensar a organização e associação de cidadãos, a construção de democracias mais participativas para a melhoria da qualidade de vida dos cidadãos e para o desenvolvimento sustentável das comunidades.

É crescente o número de pensadores e atores sociais que têm apresentado concepções relacionadas aos debates sobre a necessidade de valorizar e priorizar o associativismo civil voltado a ações que promovam o fortalecimento e o desenvolvimento social local. Nos últimos anos, importantes trabalhos foram produzidos nesse campo, entre os quais se destacam os elaborados por Hazel Henderson (1996; 2003); David C. Korten (2001); Ladislau Dowbor (2001) e Augusto de Franco (2003).

Uma significativa parcela dos autores dessa abordagem teórica está ligada à Economia e Administração, e apresenta crítica ao paradigma vigente, segundo o qual o desempenho econômico das sociedades seria a melhor forma de avaliar o desenvolvimento social, tanto de países inteiros quanto de localidades específicas. 
Segundo Hazel Henderson (1996), após o final da Guerra Fria, a difusão do capitalismo de mercado e da guerra econômica competitiva se exacerbou. Em síntese, segundo a autora, a ênfase no globalismo financeiro competitivo e a diminuição dos direitos e dos espaços de participação dos cidadãos observados nas últimas décadas alarmaram indivíduos e grupos sociais em todo o mundo. Dessa forma, esses indivíduos e grupos procuraram apresentar um novo paradigma de organização da sociedade, baseado na cooperação, no aperfeiçoamento das ferramentas democráticas de participação direta ou representativa e na preocupação com construção de formas de desenvolvimento que se mostrassem sustentáveis, satisfazendo as necessidades das pessoas e comunidades atuais sem comprometer a capacidade das gerações futuras de garantir a sua sobrevivência.

De modo geral, esses autores apresentam vigorosas críticas ao capitalismo nos dias atuais. David C. Korten (2003, p. 13) afirma, em seu livro O Mundo Pós-Corporativo, que "[...] sob o capitalismo, a democracia é objeto de leilão e o mercado está sujeito ao planejamento centralizado de mega-corporações globais [...]". A questão da busca por alternativas ao sistema capitalista atual é uma constante nessa abordagem. Entretanto, as sugestões apresentadas diferem das soluções indicadas por pensadores marxistas. A ampliação do Estado tradicional não é visto como a alternativa mais adequada.

Em verdade, o domínio do grande capital e da propriedade privada como solução para os problemas atuais é tão criticado quanto a ampliação dos equipamentos de Estado tal como são conhecidos na atualidade. A crescente complexidade das sociedades, em grande parte vinculada à urbanização das populações, impediria a adoção de soluções simplificadas ou já testadas anteriormente e que se mostraram ineficientes. Sobre isso, Henderson apresenta, de forma bastante precisa, uma visão dominante entre os autores dessa abordagem ao afirmar que:

À medida que as sociedades ocidentais têm se tornado mais tecnologicamente complexas e interdependentes, a simples polaridade ou isto/ou aquilo, conservador/liberal [...] é incapaz de canalizar a multiplicidade de questões e os debates multidimensionais que são necessários. (HENDERSON, H., 1996, p. 276).
Esses pensadores e atores sociais sugerem o fortalecimento dos espaços locais e o incentivo à participação dos cidadãos nos processos de governança local e global. O espaço local é aqui compreendido como a comunidade onde os cidadãos residem, trabalham e convivem em seus cotidianos. $\mathrm{O}$ espaço global diz respeito às macrorregiões nacionais e internacionais.

O fato de a temática da governança global emergir como uma das preocupações dos autores dessa abordagem não é contraditório. Isso porque eles apontam que é importante a articulação cuidadosa entre os problemas e soluções empreendidas localmente e as políticas e os debates realizados de modo global, seja no espaço dos governos federais ou dos grandes blocos econômicos.

A noção de governança foi definida por Pierre Calame (2004, p. 20) como "[...] a capacidade das sociedades humanas para se dotarem de sistemas de representação, de instituições, de regras, de procedimentos, de meios de avaliação, de processos, de corpos sociais capazes de gerir as interdependências de maneira pacífica".

Segundo o autor, na atualidade, é necessário redefinir as relações entre público e privado, como também entre os governos, empresas e sociedade civil. Essa redefinição, afirma Calame, deve pautar-se pelos interesses e necessidades dos cidadãos, de modo que as decisões econômicas e políticas passem a refletir os interesses das comunidades, em âmbito local, e do conjunto dos cidadãos de uma macrorregião no tocante às políticas e decisões mais abrangentes.

Nesse sentido, é preciso criar ou aperfeiçoar espaços de debate e de decisão locais, de modo a ampliar e fortalecer o poder local, definido por Dowbor (2004) como a capacidade de uma localidade, município, bairro ou quarteirão de empreender autotransformações econômicas e sociais. Dito de outra forma, essa abordagem de associativismo civil sugere que se fortaleça a democracia participativa e que os cidadãos tomem parte dos debates e decisões relacionadas aos problemas que suas comunidades enfrentam em vez de serem mantidas apenas as formas representativas de democracia e a consequente manutenção das esferas decisórias distantes daqueles que vivenciam os problemas enfrentados no cotidiano comunitário. Para Dowbor (2001, p. 13), a grande 
questão que se impõe hoje se vincula à necessidade de "reconstrução, ou estruturação da relação entre a sociedade civil e as diversas macro-organizações, estatais, privadas, que de fato nos dirigem".

Além do conceito de poder local, a noção de capital social também surge como ponto central nesta abordagem. Capital social, assim como outros conceitos da área social, não tem delimitação consensual. As definições mais correntes sinalizam que:

O capital social pode ser visto como um fenômeno subjetivo, composto de valores e atitudes que influenciam como as pessoas se relacionam entre si. Inclui confiança, normas de reciprocidade que auxiliam as pessoas a transcender relações conflituosas e competitivas para conformar relações de ajuda mútua. (KENETH apud KLIKSBERG, 2001, p. 117).

Muitos dos autores do DSL se interessam, particularmente, pelo debate sobre a necessidade de superação do modelo competitivo presente em grande parte das sociedades atuais. A cultura da cooperação tem importância dentro das teorias e práticas dos atores sociais ligados às propostas de Desenvolvimento Social Local. Henderson (1996) levanta um conjunto de situações em que empresas, governos e sociedade civil atuaram de forma colaborativa por meio do desenvolvimento de atitudes que a autora denominou estratégias ganha-ganha. Korten, Henderson, Dowbor, Calame e outros compreendem que é fundamental que as "empresas e os governos, bem como a sociedade civil, podem desempenhar os seus papéis de maneira mais efetiva. O desenvolvimento social é uma responsabilidade conjunta sem a qual não haverá estabilidade, paz e crescimento [...]" (HENDERSON, 1996, p. 332).

As ONGs são vistas como parte importante desse processo, pois podem atuar na mobilização e articulação de pessoas, no incentivo à discussão sobre as questões locais e globais, na fiscalização de ações governamentais e do setor privado, na participação do debate e implementação de políticas públicas, na oferta de serviços de forma eficiente às comunidades, entre outras atividades.

As principais críticas apresentadas a essa abordagem se referem à dificuldade de construção efetiva de processos de desenvolvimento local que não se constituem em casos isolados do contexto político, econômico e social mais amplo. A despeito da insis- tência dos autores do DSL em indicar a necessidade de fortalecer os processos que articulem a governança e a democracia ativa em âmbito local e também global, uma crítica bastante frequente a essa abordagem é que as práticas concretas próprias de incentivo ao DSL favoreceriam o afastamento dos cidadãos dos debates mais amplos da sociedade, isto é, as comunidades ficariam excessivamente preocupadas com questões relacionadas às localidades e pouco atentas aos temas de interesse de toda a sociedade.

No Brasil, alguns autores têm abordado a questão do DSL, como Augusto de Franco, Peter Spink e Ladislau Dowbor. Observa-se, entre diversos atores sociais que atuam em ONGs, um interesse bastante específico por metodologias de incentivo ao desenvolvimento social local, tais como a Agenda 21 e o Desenvolvimento Local Integrado e Sustentável (DLIS). Registram-se, no país, algumas iniciativas de organizações, agências educacionais e governos estaduais e federal de incentivo ao Desenvolvimento Social Local por meio da utilização das metodologias citadas. Algumas experiências de DSL foram realizadas pela Agência para o Desenvolvimento da Educação e pelo Serviço Nacional de Aprendizagem Comercial de São Paulo - Senac-SP.

Muito provavelmente, a metodologia de incentivo ao Desenvolvimento Social Local que se tornou mais conhecida no Brasil é o DLIS, que surgiu com base nos esforços de diversas organizações e atores sociais e foi amplamente difundida após ter sua utilização por municípios do país incentivada durante o governo do ex-presidente Fernando Henrique Cardoso. Augusto de Franco é o principal entusiasta e teórico do DLIS, definido por ele como:

\section{[...] um modo de promover o desenvolvimento que possibilita o surgimento de comunidades mais sus- tentáveis, capazes de: suprir suas necessidades ime- diatas; descobrir ou despertar suas vocações locais e desenvolver suas potencialidades específicas; e fomentar o intercâmbio externo aproveitando-se de suas vantagens locais. (FRANCO, 1999, 176).}

O DLIS é apresentado por Franco como um método de desenvolvimento local composto por um conjunto extenso de passos e sugestões a serem seguidos por atores sociais, como prefeitos, vereadores, lideranças comunitárias, entre outros. Franco afirma, em sintonia com os autores 
apresentados na exposição inicial dessa abordagem, que o desenvolvimento social local, de modo global, e a metodologia DLIS, em particular, são inovadores, pois não consideram o desenvolvimento econômico como centro de suas preocupações, e sim a melhoria da qualidade de vida e a conquista de formas sustentáveis de vida pelos cidadãos e comunidades.

$\mathrm{O}$ que distingue os autores anteriormente mencionados dessa Abordagem e Franco (2004) é a postura funcional ao projeto capitalista de sociedade assumida por este teórico, o qual sugere: a) a diminuição da oferta de recursos estatais para o estímulo do desenvolvimento das localidades; b) que as populações locais estabeleçam parcerias entre os indivíduos da própria localidade onde vivem e com empresas e governos, para a execução de programas criativos de desenvolvimento do capital humano e social; c) que a postura dos governos respeite o seguinte lema - não "[...] satisfazer necessidades das populações, apostar nos ativos que toda a comunidade possui" (FRANCO, 2004, p. 12); d) identificar as potencialidades das pessoas e das comunidades e dinamizar os recursos que, supostamente, já existem na comunidade, mas se encontram adormecidos em função da sua incapacidade de alavancar novos meios de desenvolvimento; e) a assunção de responsabilidade pela resolução dos problemas locais pela própria comunidade, que promoveria seu desenvolvimento sem esperar do poder público ou do setor privado a solução para as suas mazelas; f) estímulo constante à capacidade empreendedora de pessoas e grupos que, de acordo com Franco, se tornariam responsáveis por articular e animar a coletividade a exercitar sua criatividade, o que traria soluções para os problemas econômicos, sociais e políticos locais; g) por fim, o receituário de Franco prescreve que as comunidades locais partilhem objetivos comuns que conduzam a um futuro desejado por todos aqueles que vivem em um mesmo espaço.

Analogamente ao que ocorre na abordagem norte-americana de Terceiro Setor, Augusto de Franco afirma que seria por meio dos interesses de pequenos grupos, do sentimento de autorresponsabilidade e da criatividade das pessoas que emergiria o desenvolvimento de uma comunidade. $\mathrm{O}$ autor sugere, entrementes, que as pessoas e comunidades que não alcançam o desenvolvimento socioeconômico adequado a uma vida de boa qualidade seriam res- ponsáveis por seu próprio fracasso. Portanto, seriam a comunidade local e as pessoas que a compõem as causadoras do seu infortúnio econômico e social. Para Franco, a ausência de atenção e investimentos estatais e a exploração da parcela pauperizada da população pelos grupos enriquecidos nada teria a ver com o baixo desenvolvimento das comunidades.

Um autor radicado no Brasil, mas de visão bastante distinta daquela apresentada por Franco, é Ladislau Dowbor, que costuma abordar temas vinculados ao Desenvolvimento Social Local, Gestão Social e Poder Local. De modo semelhante à Henderson e Korten, o capitalismo é visto por Dowbor como um sistema de produção cuja hegemonia tem gerado: o êxodo rural e a explosão das populações urbanas, ataques aos direitos humanos, concentração das tecnologias, injustiças econômicas, entre outros. Para o autor, o capitalismo é um sistema eficiente para produzir, mas ineficiente para distribuir riquezas. $\mathrm{O}$ poder centralizado e rígido estatal, incapaz de apresentar respostas dinâmicas e específicas para os problemas das comunidades, também é alvo de críticas por Dowbor. Para ele, a sociedade precisa se rearticular, de modo a apropriar-se da gestão do seu desenvolvimento. A criação e o aperfeiçoamento de sistemas horizontais, interativos e mais participativos de gestão social são aspectos fundamentais para o enfrentamento dos problemas observados nas sociedades complexas contemporâneas.

O autor reconhece que esta percepção está longe de ser dominante, mas destaca que os organismos multilaterais ligados ao capital afirmam que as sociedades capitalistas atuais não são sustentáveis, dado o nível de deterioração e exclusão sociais que o sistema criou.

O teórico sugere, como forma de viabilizar de modo gradual e crescente as sociedades atuais, que o poder local seja ampliado, dotando os municípios de competência e possibilidades para a autotransformação (DOWBOR, 1995). A descentralização do poder político, tornando-o cada vez mais local, assim como o incremento das economias nos municípios é, para Dowbor, um processo que precisará efetivar-se amplamente para a melhoria da qualidade de vida das populações.

As ONGs são percebidas pelo autor como importantes elementos de articulação com o Estado para participação cidadã (KILSZTAJN; DOWBOR, 
2001). Entretanto, o autor não confunde as ONGs com o conjunto da sociedade civil, como ocorre na Abordagem Norte-Americana de Terceiro Setor, e ressalta que o social não está atrelado unicamente às parcelas organizadas e institucionalizadas da sociedade civil. Pelo contrário, propõe que o social seja uma dimensão de todas as nossas atividades e, portanto, foco do Estado, das empresas e dos grupos sociais organizados e representados por ONGs.

O papel das ONGs, para Dowbor, não é realizar ações próprias do Estado, substituindo-o, mas agir como articulador e organizador das forças sociais.

\section{Análise das matrizes teóricas sobre Associativismo Civil apresentadas pelos formadores de um curso de formação de trabalhadores para ONGs}

Essa pesquisa partiu do pressuposto que a formação de trabalhadores para a atuação em ONGs não deve prescindir de oferecer, aos participantes do processo, a oportunidade de conhecer e examinar os fundamentos teóricos sobre associativismo civil que compõem o cenário contextual em que essas organizações estão inseridas. As matrizes, usadas como categorias analíticas ou teóricas deste trabalho, apresentadas anteriormente, foram: Terceiro Setor - abordagens Norte-Americana e Crítica - e Desenvolvimento Social Local (DSL). Este estudo, conforme menções anteriores, foi dedicado ao exame das prescrições sobre associativismo civil realizadas pelos formadores de trabalhadores para ONGs, em um curso específico. As menções seguintes, relativas aos sujeitos do estudo, foram feitas de modo a não identificá-los. Optou-se, portanto, por denominalos "formador A"; "formador B" e "coordenador do curso".

A análise dos documentos relativos aos conteúdos temáticos do curso Formação de Trabalhadores para ONGs permitiu observar que, entre os três módulos constitutivos do processo formativo, é no Módulo 1, com duração de 52 horas e voltado para o tema geral "contexto social, político e econômico", que se encontra a maior ênfase e volume de prescrições feitas pelos formadores acerca das bases conceituais sobre as ONGs e a apresentação das matrizes sobre associativismo civil que permeiam todo o curso.
Os dados recolhidos sugerem que há uma forte adesão do curso à abordagem Norte-Americana de Terceiro Setor desde o princípio das atividades do primeiro módulo. O depoimento do formador " $\mathrm{A}$ " reforça essa afirmação: “[...] temos já no início do curso uma base teórica muito boa de Terceiro Setor. Os alunos (trabalhadores em formação) estudam os objetivos e papel do Terceiro Setor. Isso é importante porque dá a base sobre ONGs e Terceiro Setor que os alunos precisam para os próximos módulos do curso" (Formador “A”, Entrevista semidiretiva, 2012).

De acordo com o projeto pedagógico e as ementas dos módulos do curso, durante a formação são abordados temas em sintonia com a visão Norte-Americana de Terceiro Setor, tais como: captação de recursos em empresas e órgãos governamentais; elaboração e desenvolvimento de projetos sociais; eficiência nos serviços oferecidos à comunidade; estabelecimento de parcerias intersetoriais.

É muito importante que os alunos saibam sobre captação de recursos, parcerias com os outros setores (governamental e empresarial) e sobre como elaborar, apresentar e vender um projeto para possíveis parceiros ou financiadores. É isso que faz com que uma ONG alcance a sustentabilidade financeira. Nós queremos que o educador que estamos formando, possa contribuir com a gestão e o fortalecimento da organização em que trabalha ou vai trabalhar. (Coordenador do Curso Formação de Trabalhadores para ONGs, Entrevista semidiretirva, 2012).

Os testemunhos do formador e do coordenador do curso explicitam o seu alinhamento aos princípios do Terceiro Setor, sob enfoque norte-americano. As indicações feitas pelos entrevistados têm relação direta com os quatro desafios das ONGs, que caracterizam a perspectiva de Terceiro Setor em tela, e que foram definidos por Falconer (1999; 2001), inspirado por Léster Salamon, a saber: 1. Obtenção de sustentabilidade funcional e financeira; 2. Alcance de legitimidade das ONGs como espaços relevantes de debates e ação por parte dos cidadãos; 3 . O desenvolvimento de formas eficientes de realizar os serviços que as ONGs costumam prestar. 4. O aperfeiçoamento da capacidade de colaboração com o governo, com o setor privado e entre as próprias ONGs.

A ementa de uma disciplina específica do módulo 1 do curso, denominada $O$ Terceiro Setor, 
as ONGs e Cenários Social, Político e Econômico, aponta que somente a noção de Terceiro Setor como forma de analisar as possibilidades de associativismo civil seria contemplada no curso: “[...] será feita a análise do Terceiro Setor e dos contextos social, político e econômico no qual estão inseridas, identificando e reconstruindo concepções sobre as ONGs e seu papel social e político" (Plano Pedagógico do Curso Formação de Trabalhadores para ONGs, Ementa da Disciplina O Terceiro Setor, as ONGs e Cenários social, politico e econômico, do curso Formação de Trabalhadores para ONGs, 2011, p. 01).

A percepção dos formadores sobre o que define e confere unidade ao trabalho das ONGs tem proximidade com a perspectiva Norte-Americana do Terceiro Setor:

A gente espera que o pessoal que está participando do curso vá percebendo o quanto é fundamental para as pessoas ter uma postura de solidariedade e interesse pelo outro. Sabemos que não é isso que vai resolver (os problemas sociais). É preciso se organizar, ver quais os problemas que precisam ser enfrentados e trabalhar com as outras pessoas para conseguir melhorar as comunidades e a sociedade. (Formador "B", Entrevista semidiretiva, 2012).

A concepção de ONGs que os formadores apresentam aos trabalhadores em capacitação reproduz o pensamento dos teóricos e ideólogos do Terceiro Setor. Para o formador "A", o que confere unidade à atividade das ONGs são valores como a solidariedade. A organização de pessoas em torno de seus problemas ou das dificuldades enfrentadas localmente por pequenas comunidades é que representaria o foco de atenção das ONGs e dos indivíduos que pretendem se organizar para a atuação no campo social. A inspiração dos autores da abordagem Norte-Americana do Terceiro Setor é percebida com ênfase. Salamon afirma que aquilo que o define, determina e confere unidade ao conjunto das ONGs e demais organizações da sociedade civil é a incorporação de uma gama de valores, como "[...] altruísmo, compaixão, sensibilidade para com os necessitados [...]" (SALAMÓN, 2005, p. 92). As perspectivas críticas ao Terceiro Setor são rejeitadas pelos formadores e coordenador do curso. $\mathrm{O}$ depoimento do formador "B" é representativo:
Nós sabemos que há algumas críticas ao Terceiro Setor e às ONGs. Mas é de um pessoal marxista radical, que não vê que o mundo mudou. Pode parecer forte dizer isso, mas a verdade é que não dá para considerar muito. Eles só criticam e não apresentam propostas para a sociedade. A gente acaba nem trabalhando muito com esses autores no curso, porque parece que não tem muito a acrescentar e o curso pretende ser bastante propositivo. (Formador "B", Entrevista semidiretiva, 2012).

O questionamento à abordagem crítica ao Terceiro Setor, nos termos que parecem orientar a visão transmitida aos participantes do curso, reproduz a contestação corrente a essa perspectiva, em que as relações dos autores críticos ao Setor com o marxismo ensejariam uma capacidade reduzida de perceber que as sociedades contemporâneas se diversificaram e se tornaram extremamente complexas. O paradigma clássico marxista não permitiria oferecer respostas adequadas ao conjunto dos problemas vivenciados pelas comunidades contemporâneas.

Os formadores do curso prescrevem uma visão de associativismo civil fundado na organização de pequenos grupos e consideram que a estruturação e ação coletiva de grandes grupos de trabalhadores empobrecidos não seriam adequadas à construção de uma sociedade democrática, o que parece aproximar o curso do ideário de Tocqueville, autor que inspirou a contemporânea perspectiva de Terceiro Setor.

O que a gente percebe no curso é que a sociedade civil tem um propósito maior do que servir à bagunça ou conflitos de radicais, como esse pessoal sindicalista ou do MST (Movimento dos Trabalhadores Rurais Sem-Terra). O que a gente busca com as ONGs é a melhoria efetiva da vida das pessoas que estão nas comunidades, oferecendo serviços bons, que ajudem [...]. (Formador "A", Entrevista semidiretiva, 2012).

Aparentemente, o que emerge da visão de associativismo civil norteadora do curso é uma perspectiva de ação e organização política dos cidadãos também influenciada pela abordagem norte-americana de Terceiro Setor. No curso, o principal papel e direito dos cidadãos é, de modo simplificado, associar-se livremente e lutar por seus direitos; visão indicativa de vínculos a Tocqueville, conforme citamos anteriormente neste artigo. Para Tocqueville, a expressão máxima de liberdade política dos cidadãos 
é o direito à associação livre e solidária em pequenos grupos, em torno da defesa dos seus direitos.

Os dados que emergiram das entrevistas permitem apontar que a noção de democracia é abordada no curso, ainda que de modo ligeiro. A única preocupação em relação à matriz manifestada pelos formadores, foi que os trabalhadores em formação compreendessem que o papel das ONGs nas comunidades seria o de articular a população local para questionar os representantes políticos, como vereadores, deputados, prefeitos, governadores, etc. Essa seria uma prática, de acordo com os formadores, genuinamente democrática.

A gente tenta trabalhar o que é importante, educar a comunidade para o questionamento e a cobrança das autoridades. Você precisa conhecer seu vereador, aquele que você elegeu para poder questionar. No curso trabalhamos isto. Já chegamos a fazer visitas, com os alunos, à câmara dos vereadores, mas nesta última turma não foi possível. O importante é que eles vejam que é possível cobrar as autoridades para melhorar as condições de vida da população que está no entorno da ONG em que eles (os trabalhadores em formação) trabalham. (Coordenador do curso Formação de Trabalhadores para ONGs, Entrevista semidiretiva, 2012).

Não são mencionados no curso aspectos relacionados à matriz chamada de desenvolvimento social local, que tem tido grande destaque na literatura acadêmica e nas práticas próprias do associativismo civil brasileiro.

\section{Considerações Finais}

O estudo apresentado teve como objetivo examinar e compreender as matrizes ou abordagens teóricas sobre associativismo civil que são prescritas pelos formadores de um curso de capacitação de trabalhadores para ONGs.

Considerando as entrevistas realizadas com formadores e coordenador do curso e, também, as informações disponíveis nos documentos analisados, pode-se afirmar que, entre as diferentes abordagens de associativismo civil, somente a perspectiva Norte-Americana de Terceiro Setor é trabalhada no processo educativo do curso. Registramos a ausência de debates aprofundados sobre as demais matrizes utilizadas como referências teóricas desta pesquisa ou outras presentes na literatura especializada. Em lugar das matrizes teóricas de associativismo civil, o curso confere ênfase a temáticas como captação de recursos, eficiência na prestação de serviços, estabelecimento de parcerias interssetoriais que são relevantes para o Terceiro Setor nos termos apresentados por teóricos como Salamon (2005) e Falconer (1999; 2001).

Um programa ou curso que pretende capacitar trabalhadores para uma determinada área deve oferecer aos seus alunos, segundo consideramos, a oportunidade de conhecer e refletir sobre as diferentes perspectivas sociais, culturais, econômicas, culturais e políticas que estão presentes ou influenciam seu campo de atuação. Dessa forma, parece adequado que um processo formativo de trabalhadores para ONGs ofereça aos participantes a oportunidade de análise e reflexão crítica acerca das diferentes matrizes sobre associativismo civil que estão subjacentes à atuação daquelas organizações. É importante apontar que a ausência de um adequado incentivo ao debate pelos formadores participantes desta pesquisa sobre o que são ONGs e as múltiplas abordagens de associativismo civil, torna frágil a formação dos trabalhadores, dado que eles não entraram em contato com os referenciais teóricos básicos para a análise sociopolítica do seu campo de atuação profissional.

É relevante que o trabalhador que está se capacitando para atuar nas ONGs seja capaz de identificar, por meio da observação e da prática cotidiana de trabalho nessas organizações, as perspectivas relacionadas às teorias que orientam o trabalho, de modo geral, e que norteiam uma única organização, com a qual o trabalhador se encontra vinculado. Isso tende a permitir ao profissional optar, com maior clareza, pelo local em que pretende atuar e, também, elaborar projetos e apresentar propostas compatíveis com a visão de ONG e associativismo civil da organização em que está ingressando, como funcionário ou voluntário. Ainda, que seja capaz de articular a sua visão de mundo e de modelo geral de organização política, econômica e social com a perspectiva de associativismo civil que norteia sua ação em uma ONG.

Não desconhecemos que a atual legislação brasileira que orienta a criação e funcionamento das ONGs, denominada marco legal do Terceiro Setor, está vinculada à Abordagem Norte-Americana 
(SZAZI, 2006). Entretanto, isso não significa que os trabalhadores de ONGs devam desconhecer as abordagens distintas da norte-americana de Terceiro Setor, visto que, ao ignorar outras matrizes de associativismo civil, o trabalhador não estará apto a analisar criticamente a pertinência da atual legislação sobre a área em que trabalha ou pretende atuar.

A ênfase na Abordagem Norte-Americana acaba, muito provavelmente, por inibir a formação, no âmbito do curso estudado, de atores sociais capazes de mobilizar e articular grupos e comunidades, pois, na abordagem adotada, há incentivo à profissionalização do Terceiro Setor no tocante, principalmente, aos processos de gestão das organizações. Porém, pouco destaque é conferido à formação efetiva de pessoas e grupos para o protagonismo dos processos de desenvolvimento comunitário.

Por fim, acreditamos que um curso de formação de trabalhadores para a atuação em ONGs deve ter como objetivo central capacitar profissionais comprometidos com: a emancipação humana; a melhoria da qualidade de vida de indivíduos e da coletividade; a mobilização e articulação das comunidades para a busca ativa de soluções de seus problemas; a ampliação das possibilidades de indivíduos e comunidades participarem de forma democrática ativa nos processos decisórios e de gestão das localidades e da sociedade de modo geral; e a superação das condições de exploração das parcelas empobrecidas da população, devido ao modelo capitalista de organização societal.

\section{Referências}

ANDRÉ, M. Estudo de caso em pesquisa e avaliação educacional. Brasília: Liber, 2005.

ANDRÉ, M.; LÜDKE, M. Pesquisa em educação: abordagens qualitativas. São Paulo: E.P.U., 1986. - (Temas Básicos de Educação e Ensino).

ANDRÉ, M. Etnografia da prática escolar. 9. ed. Campinas, SP: Papirus, 2003.

Estudo de caso em pesquisa e avaliação educacional. Brasília: Liber, 2005.

ANTUNES, R. Os sentidos do trabalho: ensaio sobre a afirmação e negação do trabalho. 5.ed. São Paulo: Boitempo, 2002.

CALAME, P. (Coord.). Princípios para a governança no século XXI. São Paulo: Instituto Polis, 2004.
CHIZZOTTI, A. Pesquisa em ciências humanas e sociais. 11.ed. São Paulo: Cortez, 2010.

DOWBOR, L. O mosaico partido: a economia além das equações. 2. ed. Petrópolis, RJ: Vozes, 2000.

Tecnologias do conhecimento: os desafios da educação. Petrópolis, RJ: Vozes, 2001a.

A reprodução social: descentralização e participação: novas tendências. São Paulo, 2001b. Disponível em: <http://dowbor.org>. Acesso em: 20 jan. 2013.

Democracia econômica: no horizonte das teorias 2006. Disponível em <http://dowbor.org>. Acesso em: 26 jan. 2013.

FALCONER, A. A promessa do terceiro setor: um estudo sobre a construção do papel das organizações sem fins lucrativos e do seu campo de gestão. 1999. Dissertação (Mestrado em Administração). Universidade de São Paulo, 1999.

Recursos privados para fins públicos. São Paulo: Peirópolis, 2001

FELDMANN, M. G. Escola pública: representações, desafios e perspectivas. In: ALONSO, M. O trabalho docente: teoria e prática. 2.ed. São Paulo: Pioneira Thompson, 2003.

FERNANDES, R. C. O que é Terceiro Setor? In: IOSCHPE, E. B. (Coord.). Terceiro setor e desenvolvimento sustentado. Rio de Janeiro: Paz e Terra, São Paulo: GIFE, 2005. p. 25-34.

FRANCO, A. Desenvolvimento local integrado. São Paulo: Cortez, 1999.

O lugar mais desenvolvido do mundo: investindo no capital social. São Paulo: AED, 2004.

FRANCO, E. K. Currículo por projetos: inovação do ensinar e aprender na educação superior. 2008. Dissertação (Mestrado em Educação: Currículo)-Pontifícia Universidade Católica/ PUC-SP, São Paulo, 2008.

FUKUYAMA, F. O fim da história e o último homem. São Paulo: Rocco, 1992.

GOHN, M. G. Educação não formal: um novo campo de atuação. Ensaio: avaliação, políticas públicas em educação. Rio de Janeiro: Fundação Cesgranrio, v. 6, n. 21, p. 441-560, 1998.

O protagonismo da sociedade civil: movimentos sociais, ONGs e redes solidárias. São Paulo: Cortez, 2005. (Coleção Questões da nossa Época, v. 123)

Educação não formal na pedagogia social. In: CONGRESSO INTERNACIONAL DE PEDAGOGIA SOCIAL. 1. São Paulo, 2006. Anais...

HENDERSON, H. Construindo um mundo onde todos ganhem. São Paulo: Editora Cultrix/Amana-Key, 1996. 
. Além da globalização: modelando uma economia global sustentável. São Paulo: Editora Cultrix/Amana-Key; 2003.

INSTITUTO BRASILEIRO DE GEOGRAFIA E ESTATÍSTICAS. As fundações privadas e associações sem fins

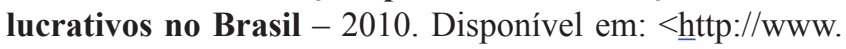
ibge.gov.br/home/presidencia/noticias/noticia_visualiza. php?id_noticia $=2278 \& i d \_p a g i n a=1>$. Acesso em: 10 fevereiro 2013 .

KILSZTAJN, S.; DOWBOR, L. (Orgs.). Economia social no Brasil. São Paulo: Senac-SP, 2001.

KLIKSBERG, B. Falácias e mitos do desenvolvimento social. São Paulo: Cortez; Brasília: UNESCO. 2001.

KORTEN, D. C. O mundo pós-corporativo: vida após o capitalismo. Petrópolis, RJ: Vozes; 2001.

MONTAÑO, C. Terceiro setor e questão social: crítica ao padrão emergente de intervenção social. São Paulo: Cortez, 2007.

NAVARRO, Z. Mobilização sem emancipação: as lutas sociais dos sem-terra no Brasil. In: SANTOS, B. S. (Org.). Produzir para viver: os caminhos da produção não capitalista. Rio de Janeiro: Civilização Brasileira, 2002.

ONG FORMADORA. Proposta estratégica da ONG Formadora. São Paulo, 2011.

. Plano pedagógico do curso Formação de TrabaIhadores para ONGs. São Paulo, 2012. - (documento de circulação interna)

PEREZ, D. Formação de educadores para o Terceiro Setor. 2004. Dissertação (Mestrado em Educação, Arte e História da Cultura) - Universidade Presbiteriana Mackenzie, São Paulo, 2004

Formação de professores para organizações não governamentais/ONGs. 2009. Tese (Doutorado em Educação: Currículo) - Pontíficia Universidade Católica de São Paulo/PUC-SP, São Paulo, 2009.

. Análise de um processo formativo de professores para a educação não formal realizada em organizações não governamentais. Revista Educação, Cultura e Sociedade. Sinop: UNEMAT, v. 3, n.1 (jan./jun., p. 149-162, 2013.

PETRAS, J. Neoliberalismo: América Latina, Estados Unidos e Europa. Blumenau: Furb, 1999. - (Coleção Sociedade e Ambiente, n.3).

Globaloney. El lenguaje imperial, los intelectuales y la izquierda. Buenos Aires: Antídoto, 2000.

PUTNAM, R. Comunidade e democracia: a experiência da Itália moderna. Rio de Janeiro: Editora da Fundação Getúlio Vargas, 1996.

SALAMON, L. Estratégias para fortalecimento do Terceiro Setor. In: IOSCHPE, E. B. (Coord.). Terceiro setor e desenvolvimento sustentado. Rio de Janeiro: Paz e Terra, São Paulo: GIFE, 2005.

(Org.). The state of nonprofit America. 2.ed., Washington: Brookings Institution Press, 2012.

SPINK, P. A democratização do poder local: gestão social na ótica subnacional. In: SZAZI, E. Terceiro setor: regulação no Brasil. São Paulo: Peirópolis, 2006.

TOCQUEVILle, C. A. A democracia na América: leis e costumes de certas leis e certos costumes políticos que foram naturalmente sugeridos aos americanos por seu estado social democrático [1835]. Trad. Eduardo Brandão. São Paulo: Martins Fontes, 1998.

A democracia na América: sentimentos e opiniões [1835]. Trad. Eduardo Brandão. São Paulo: Martins Fontes, $1835 / 2000$.

TORRES, C. A.; BURBULES, N. (Orgs.). Globalização e educação. Porto Alegre: ArtMed, 2004.

TRIVIÑOS, A. N. S. Introdução à pesquisa em Ciências Sociais: a pesquisa qualitativa em educação. São Paulo: Atlas, 1986.

Recebido em: 19 de fevereiro de 2013. Aceito em: 05 de junho de 2013.

Publ. UEPG Ci. Soc. Apl., Ponta Grossa, 21 (1): 53-71, jan./jun. 2013

Disponível em <http://www.revistas2.uepg.br/index.php/sociais> 